\title{
Physiological roles for neuromodulation via Gi/o GPCRs working through $G \beta \gamma$-SNARE interaction
}

\author{
Heidi E. Hamm ${ }^{1}$ and Simon T. Alford ${ }^{2}$ \\ Neuropsychopharmacology (2020) 45:221; https://doi.org/10.1038/s41386-019-0497-2
}

Activation of presynaptic $\mathrm{G}_{\mathrm{i} / \mathrm{o}}$-coupled receptors by hormones, neurotransmitters (NT) and neuromodulators leads to decreased neurotransmission. This decreased release provides an important control mechanism for autoreceptors to guard against over-activation, and an important homeostatic mechanism. For heteroreceptors, it is a critical component of synaptic integration mediating circuitrylevel effects. Fast membrane-delimited inhibition of secretion may occur via $\mathrm{G} \beta \gamma$ regulation of voltage-dependent $\mathrm{Ca}^{2+}$ channels (VDCCs). However, a direct interaction between $\mathrm{G} \beta Y$ and soluble $\mathrm{N}$ ethylmaleimide-sensitive factor attachment protein receptor (SNARE) proteins also leads to inhibition of exocytosis downstream of $\mathrm{Ca}^{2+}$ entry [1]. This mechanism is not only more acute and direct in controlling evoked release, leaving secondary effects of presynaptic $\mathrm{Ca}^{2+}$ unaffected, but is also able to modify components of exocytosis not available to mechanisms that control release probability. These include modifying the concentration of neurotransmitter released [2] by interacting with a region of the SNARE complex that controls fusion rate, but also modifying spontaneous release, which has important roles in its own right. The same synapses can have different $\mathrm{G}_{\mathrm{i} / \mathrm{o}}$-GPCR-triggered modulation of neurotransmitter release by different mechanisms. For example, in hippocampal neurons, $\mathrm{GABA}_{B}$ receptors cause decreased $\mathrm{Ca}^{2+}$ entry and $5 \mathrm{HT}_{1 \mathrm{~b}}$ receptors inhibit exocytosis by directly acting on SNAREs at the same synapse: this allows for presynaptic neural integration [3]. What could be the mechanistic basis of this specificity? There is considerable evidence that unique $G \beta Y$ isoforms play specific roles in mediating interactions with both receptors and effectors. Our recent in vivo proteomic studies of $\mathrm{G} \beta \gamma$ specificity suggest that it might come from receptor selection of particular $G \beta \gamma$ subunits [4], and the affinity of those $G \beta \gamma^{\prime} s$ for the SNARE complex (unpublished).

Understanding of the physiological role of GBY-SNARE interaction has lagged because of a lack of tools. But recent progress in understanding the molecular basis of this interaction, in particular a target for G $3 y$ at the C-terminal of SNAP25 [5] has yielded a transgenic SNAP25 33 mouse with a selectively disturbed G $\beta \gamma$-SNARE interaction. This mouse has normal evoked exocytosis and normal GABAergic inhibition of VDCC, but disturbed inhibition of exocytosis through G $\beta Y$-SNARE interaction. The SNAP25 33 mouse provides clear evidence that the GBY-SNARE locus is physiologically important for regulation, because it has a number of interesting phenotypes both central and peripheral, including elevated stress-induced hyperthermia, impaired supraspinal nociception, defective spatial learning, impaired gait, and depressive-like behavior [6].

Most interestingly, the two G $\beta \gamma$-mediated inhibitory mechanisms, co-occurring at the same synapse, are synergistic with each other: a completely unexpected result. This observation suggests that combinations of neurotransmitters may shape neuromodulation, potentially giving rise to novel effects on circuits. Thus, synaptic integration can occur as much presynaptically as postsynaptically. The specificity of the two mechanisms raises the possibility that targeting the G $\beta Y$-SNARE interaction may be a therapeutic strategy, and, further, that therapeutic pairing of drugs that affect each mechanism may themselves work synergistically, an exciting possibility.

\section{FUNDING AND DISCLOSURE}

Funding for this study was provided by the NIMH, R01 MH084874, R01 MH064763, and R01 MH101679, NINDS, R01 NS111749, R01 NS052699, and NIDDK, R01 DK109204. The authors declare no competing interests.

\section{ACKNOWLEDGEMENTS}

We owe a debt of gratitude to the many research collaborators, students and postdoctoral fellows that have contributed to this project. Prior researchers include T Blackmer who started these studies, E-J Yoon, T Gerachshenko, and E Hamid. More recent contributors include Z Zurawski, A Thompson Gray, Y-Y Yim, L Brady, B Page, E Church, S Rodriguez, N Harris, M Dohn, K Hyde, D Mortlock, C Jones, and D Winder. We thank all of these scientists for their collaboration, discussions, inspiration and support.

\section{ADDITIONAL INFORMATION}

Publisher's note: Springer Nature remains neutral with regard to jurisdictional claims in published maps and institutional affiliations.

\section{REFERENCES}

1. Blackmer T, Larsen EC, Takahashi M, Martin TF, Alford S, Hamm HE. G protein $\beta Y$ subunit-mediated presynaptic inhibition: regulation of exocytotic fusion downstream of Ca2+ entry. Science. 2001;292:293-297.

2. Photowala H, Blackmer T, Schwartz E, Hamm HE, Alford S. G protein $\beta$ ysubunits activated by serotonin mediate presynaptic inhibition by regulating vesicle fusion properties. Proc Natl Acad Sci USA. 2006;103:4281-4286.

3. Hamid E, Church E, Wells CA, Zurawski Z, Hamm HE, Alford S. Modulation of neurotransmission by GPCRs is dependent upon the microarchitecture of the primed vesicle complex. J Neurosci. 2014;34:260-274.

4. Yim YY, Betke KM, McDonald WH, Gilsbach R, Chen Y, Hyde K, Wang Q, Hein L, Hamm HE. The in vivo specificity of synaptic $G \beta$ and $G \gamma$ subunits to the alpha2a adrenergic receptor at CNS synapses. Sci Rep. 2019;9:1718.

5. Gerachshenko T, Blackmer T, Yoon E-J, Bartleson C, Hamm HE, Alford S. G $\beta$ Y acts at the $C$ terminus of SNAP-25 to mediate presynaptic inhibition. Nat Neurosci. 2005;8:597-605.

6. Zurawski Z, Thompson Gray AD, Brady LJ, Page B, Church E, Harris NA, Dohn MR, Yim YY, Hyde K, Mortlock DP, Jones CK, Winder DG, Alford S, Hamm HE. Disabling the G $\beta Y$-SNARE interaction disrupts GPCR-mediated presynaptic inhibition, leading to physiological and behavioral phenotypes. Sci Signal. 2019;12:pii: eaat8595.

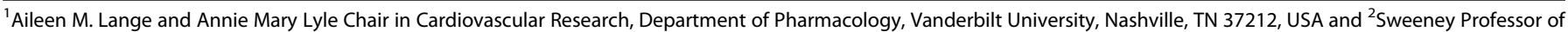
Basic Sciences and Head, Department of Anatomy and Cell Biology, University of Illinois at Chicago, College of Medicine, 808S. Wood St., Chicago, IL 60612, USA

Correspondence: Heidi E. Hamm (heidi.hamm@vanderbilt.edu) or Simon T. Alford (sta@uic.edu)
}

Published online: 2 September 2019 